\title{
Evaluation of clustering of new intramammary infections in the bovine udder, including the impact of previous infections, herd prevalence, and somatic cell count on their development
}

\author{
K. K. Reyher, ${ }^{*} \dagger^{1}$ I. R. Dohoo, ${ }^{*} \dagger$ and C. A. Muckle $\dagger$ \\ ${ }^{*}$ Canadian Bovine Mastitis Research Network, C.P. 5000, Saint-Hyacinthe, Québec, J2S 7C6, Canada \\ †Centre for Veterinary Epidemiological Research, University of Prince Edward Island, Charlottetown, PEI, C1A 4P3, Canada
}

\begin{abstract}
Evidence in the literature exists to support the theory that mastitis and intramammary infection (IMI) tend to cluster within herds, within cows, and within quarters, facts which may have overarching ramifications on mastitis management in modern dairy herds. Most previous studies, however, have been carried out on prevalent IMI instead of new IMI (NIMI), although reducing incidence of NIMI is a major step toward controlling mastitis. The Canadian Bovine Mastitis Research Network (Saint-Hyacinthe, QC, Canada) has a large mastitis database derived from a 2-yr data collection on a national cohort of dairy farms, and data from this initiative were used to investigate the effect of clustering on the acquisition of NIMI. Longitudinal milk samplings of clinically normal udders taken over several 6 -wk periods as well as samples from cows predry-off and postcalving were used $(\mathrm{n}=73,772$ quarter milk samples). Multilevel logistic models were used to evaluate the effect of location of IMI in quarters of the bovine udder previous to occurrence of an NIMI with Staphylococcus aureus, coagulase-negative staphylococci, and Corynebacterium spp. Several factors were investigated, including the number and location of quarters infected with the pathogen of interest before occurrence of an NIMI, the number of quarters infected with any other pathogen before occurrence of an NIMI (a measure of susceptibility), somatic cell count of the quarter before occurrence of an NIMI, somatic cell count of the other 3 quarters before occurrence of an NIMI, prevalence of the specific pathogen in the herd, and the average somatic cell count of the herd. The amount of variation occurring at different levels (herd, cow, and quarter) for the various pathogens was also calculated. The presence of an IMI in the ipsilateral quarter was associated with an elevated risk of an NIMI
\end{abstract}

Received May 17, 2012.

Accepted September 30, 2012.

${ }^{1}$ Corresponding author: kreyher@upei.ca occurring for all pathogens investigated. Risk of an NIMI increased considerably as herd prevalence of the pathogen rose. Substantial clustering was found at all levels, with roughly equal amounts of variation found in all 3 levels for coagulase-negative staphylococci, most variation at the cow-level for Corynebacterium spp., and most variation found at the quarter-level for Staph. aureus. Simulation was used to calculate exact values of intraclass correlation coefficients to estimate clustering within cows and within quarters - these exact values were, for the most part, lower than estimates calculated using the latent variable approach, but also increased as pathogen prevalence and number of infections in a cow at the previous sampling increased. These results of these analyses can be used to inform approaches to preventing NIMI in modern dairy operations.

Key words: new intramammary infection, clustering, intraclass correlation, previous infection

\section{INTRODUCTION}

The control of mastitis is one of the overriding concerns of the modern dairy industry. Managers of herds worldwide are striving to reduce the number of infections occurring on their farms, and addressing risk factors known to be associated with the occurrence mastitis is of the utmost importance. Animals in a particular herd tend to have more in common than animals in differing herds (similar management factors, strains of pathogens prevalent in the herd, and so on). Thus, cows within herds are not independent, and it is beneficial to reach a greater understanding of how mastitis clusters between cows (within herds) so that producers can best focus their efforts to reduce mastitis. Recently, it has been shown that the incidence rate of Staphylococcus aureus is the driving force behind its prevalence in dairy herds, and that reducing incidence of new IMI (NIMI) caused by this major pathogen can serve to reduce prevalence more than increasing elimination rate (Dufour et al., 2012a).Understanding how clustering affects the occurrence of NIMI with 
certain pathogens can serve to inform producers and researchers alike who are searching for ways to better manage the differing needs of herds (those with contagious mastitis pathogens versus those that struggle with environmental contamination, for instance).

Just as cows within a herd share commonalities, quarters within an individual cow are perhaps more alike than they are different (all the same age, stage of lactation, same immune system, and so on). It has previously been shown that subclinical mastitis (defined as an increase in SCC) occurs more often in some cows than others (Grootenhuis, 1975; Schepers et al., 1997; Barkema et al., 1997; Berry and Meaney, 2006), that IMI (the most common cause of mastitis) tend to cluster within cows (Grootenhuis, 1975; Smith and Coetzee, 1978; Rainard and Poutrel, 1984; Barkema et al., 1997; Schepers et al., 1997; Berry et al., 2003; Berry and Meaney, 2006; Robert et al., 2006) and, indeed, that some cows show an increased clinical mastitis incidence compared with others (Batra et al., 1977; Schepers et al., 1997). It has also been shown that inflammation can be caused in neighboring quarters when a specific quarter becomes infected with a mastitis pathogen (Schultze and Bramley, 1982; Wever and Emanuelson, 1989), and that cows may respond differently to treatment of mastitis (Miller, 1975; Swenson, 1979).

With this knowledge of the importance of cow-level clustering, therefore, it is certainly of interest to quantify the amount of clustering that exists as well as the influence of prevalent IMI in the cow's udder on the risk of developing new IMI. Pathogens may be passed back and forth between quarters, and this passage may be caused either by teat ends coming in contact with one another or by the transfer of pathogens through milking equipment or other fomites. Correct management of extant IMI within a cow, therefore, is necessary to prevent NIMI from occurring. Special efforts at addressing specific cows (e.g., those that always lie in dirty areas of the farm or those that have several quarters chronically infected with a pathogen) may be warranted if large amounts of cow-level clustering are present or if prevalent IMI substantially increase the risk of cows developing NIMI in other quarters.

Interdependence between quarters within cows is also of importance in mastitis research. If quarters are erroneously considered independent, studies may overestimate the effects of treatment regimens and management practices (Barkema et al., 1997; Berry and Meaney, 2006). Knowing at which level variance is highest allows further investigation to be pinpointed to the areas in which intervention is likely to be most effective or where treatment would yield the greatest benefit (Vigre et al., 2004; Berry and Meaney, 2006; Robert et al., 2006). Because quarters within cows are not independent, clustering must be taken into account when planning experiments, evaluating therapies, and even deciding to treat cows in a herd.

Furthermore, evidence exists that IMI may cluster within quarters (i.e., that a quarter may be more likely to have an infection if it has been infected before; Zadoks et al., 2001a,b), although other studies have not found this to be true (Parker et al., 2007). If quarter-level clustering were quantified, the extent to which being able to prevent an NIMI in the first instance would serve to prevent further NIMI would be directly evident. Quarters with predisposing factors for NIMI (those with stepped-on or rough teat ends, for instance) might deserve extra attention in addressing mastitis problems on a farm. Understanding to what extent having a previous infection might predispose a quarter to future NIMI may serve to motivate those in the dairy industry to accurately and expediently treat IMI.

Because decreasing the incidence of NIMI is one of the foundational tenets of mastitis control (along with reducing duration of infection), knowledge of how these new infections cluster may assist researchers and producers alike in addressing the challenges of mastitis control in the modern dairy farm. Much of the previous work concerning clustering has focused on prevalent IMI or clinical mastitis, but knowing how to prevent new infections occurring is certainly more powerful than delineating the association of factors with lower prevalence in a population. Knowledge of how NIMI cluster at different levels will allow researchers, practitioners, and producers to draw conclusions on what may predispose cows to new infections rather than simply to infection in general. It is the objective of this paper, therefore, to evaluate the associations between salient herd-, cow-, and quarter-level predictors and the occurrence of NIMI, as well as to calculate the intraclass correlations for NIMI with specific pathogens at the herd, cow, and quarter levels. These goals were achieved for the major mastitis pathogen Staph. aureus and for the minor mastitis pathogens CNS and Corynebacterium spp.

\section{MATERIALS AND METHODS}

\section{Sample Collection}

All samples were taken as part of the large data collection platform of the Canadian Bovine Mastitis Research Network (CBMRN, Saint-Hyacinthe, QC, Canada): the National Cohort of Dairy Farms (Reyher et al., 2011). Ninety-one farms were enrolled from 4 regions of Canada and sampled over 2 yr (2007 and 2008). Longitudinal quarter milk samples were col- 
lected by trained technicians from lactating cows that were considered to be clinically normal (no abnormal milk) by the producers as well as the technicians. Any signs of inflammation of the quarter were recorded, and quarters with signs of clinical mastitis were excluded from sampling. Fifteen cows per period (10 randomly selected mid-lactation cows and the 5 most recently calved cows in the herd) were enrolled on every farm for each of 4 sampling periods. Sampling periods consisting of 3 visits separated by intervals of 3 wk were independently performed during the winters of 2007 and 2008 as well as the summer of 2008. An intensive sampling period consisting of 7 weekly samplings occurred during the summer of 2007. Samples were also collected from 15 cows each year between 4 and 2 wk before dry-off and between 2 wk before dry-off and dry-off (both considered pre-dry-off samples) in 2007 and again in 2008, as well as within $24 \mathrm{~h}$ of calving and from 1 to 2 wk after calving (postcalving samples, again separately in 2007 and 2008). Subsets of cows for each of the 6 sampling periods (winter 2007, summer 2007, pre-dryoff/postcalving 2007, winter 2008, summer 2008, and pre-dry-off/postcalving 2008) were selected independently, and cows were not often included in more than 1 sampling period.

\section{Bacteriological Culture}

Milk samples were frozen and submitted to one of the bacteriology laboratories comprising the CBMRN's Mastitis Laboratory Network. Laboratories followed standardized protocols based on National Mastitis Council guidelines for bacteriological culture and species identification (Hogan et al., 1999). A milk sample from which 3 or more different species were cultured was considered contaminated, although Staph. aureus identified in these samples was enumerated.

\section{Definitions}

IMI Definition. Samples were considered to have an IMI if they cultured 100 or more $\mathrm{cfu} / \mathrm{mL}$ of the organism of interest in either a pure or mixed growth, except for CNS, where the requirement was set to 200 or more $\mathrm{cfu} / \mathrm{mL}$. The IMI definitions were chosen to balance the sensitivity (Se) and specificity $(\mathbf{S p})$ of new IMI diagnoses, based on the definitions presented by Dohoo et al. (2011b). Single samples were used; previous studies have shown that single samples are often in agreement for contagious organisms (Erskine and Eberhart, 1988), and that the Se of a single sample is better than that of duplicate samples interpreted in series and comparable to that of triplicate samples with only a marginal loss in Sp (Dohoo et al., 2011a).
NIMI Definition. An NIMI was defined as a quarter without IMI initially, but with IMI at the next subsequent sampling (usually 2 wk later for pre-dryoff and postcalving samples; 3 wk later for lactational samples taken during the winters of 2007 and 2008, and the summer of 2008; and 1 wk later for lactational samples taken during the summer of 2007). This definition meant that an NIMI needed to occur after only 1 negative sample, which is of interest particularly in the summer of 2007 data.

\section{Multilevel Logistic Regression Models}

Samples Used. A set of samples was included if it represented quarter samples from each of a cow's 4 quarters at 1 sampling period (e.g., set 1: samples from all 4 quarters taken 2 wk before dry-off in 2007; set 2: samples from all 4 quarters taken at dry-off in 2007; set 3: samples from all 4 quarters taken at one of the lactational samplings in the winter of 2007, and so on). For the multilevel logistic regression models, the presence of an NIMI in the individual quarter in question (e.g., left front quarter sample taken at dry-off in 2007) was then compared with results from the set of samples taken at the previous sampling (samples from all 4 quarters taken 2 wk before dry-off in 2007). The bacteriological status of the cow's other 3 quarters (those ipsilateral, contralateral, and diagonal to the quarter in question) on the previous sampling was evaluated.

Modeling Process. Multilevel logistic models using NIMI with a specific pathogen as an outcome were fit with the predictors listed below being common to all models. Although major pathogens such as Streptococcus uberis, Streptococcus dysgalactiae, Escherichia coli, and Klebsiella spp. were initially investigated, the low incidence of NIMI with these pathogens meant that these models did not converge. Due to perceived differences in the epidemiology of the different pathogens (especially the streptococci), analyses aggregating the species were not undertaken. Staphylococcus aureus and the minor pathogens CNS and Corynebacterium spp. were evaluated. Continuous predictors were evaluated for linearity in relation to the outcome and were investigated using fractional polynomials. When these transformations were not significant in multivariable models and did not change the other model coefficients substantially, the predictors were modeled as linear terms. Interactions were not considered. Predictors common to all models were as follows:

- lactation number (dichotomized into first lactation and second-or-greater lactation),

- days in milk at the time of sampling (linear representation), 
- sampling period (e.g., dry cow sample taken in 2007; lactating cow sample taken in summer 2008); because cows might have been randomly selected for more than 1 sampling period, observations from some cows might have been crossclassified by herd and sampling period (sampling period was included in the models as a fixed effect to account for this cross-classification),

- quarter from which the sample was taken,

- the natural logarithm transformation of the SCC $(\operatorname{lnSCC})$ of the quarter in question at the previous sampling (quadratic and cubic representation),

- a geometric mean of SCC of the cow's other 3 quarters (besides the quarter in question) at the previous sampling (linear representation),

- a susceptibility factor representing the number of quarters of that cow infected with any other pathogen at the previous sampling (this susceptibility parameter was calculated using any organism cultured by CBMRN laboratories except for "other gram-positive" organisms, which were mainly Bacillus spp. and were assumed to be associated with environmental contamination),

- pathogen-specific prevalence of IMI for individual cows,

- pathogen-specific prevalence of IMI for individual herds, and

- average herd lnSCC.

In addition to these common factors, 2 representations of the presence of an IMI with the pathogen in question at the previous sampling were evaluated using separate models. A location model included predictors for IMI presence at the previous sampling in the quarters ipsilateral, contralateral, or diagonal to the one in question. A summation model included hierarchical categorization of the number of quarters infected with that pathogen at the previous sampling. Random effects were added at the herd level to account for clustering of cows within herds, at the cow level to account for clustering of quarters within cows, and at the quarter level to account for clustering of samples within quarters (repeated measures). Statistical significance was defined as $P \leq 0.05$.

Intraclass Correlation Coefficients. The similarity between units in a particular grouping (in these analyses, samples in a specific quarter, cow, or herd) can be expressed by using an intraclass correlation coefficient (ICC; Dohoo et al., 2009). Linear models allow calculation of the ICC as the proportion of variance comprising observations at a specific level divided by the total variance. Logistic models require more complicated statistical computations, however, as the sample-level variance is on a different scale than the random effects variances for herd, cow, and quarter. Several methods for approximating the ICC for the different levels have been reviewed (Dohoo et al., 2001; Goldstein et al., 2002; Vigre et al., 2004; Browne et al., 2005).

Two methods were used in these analyses to calculate ICC. First, the latent variable approximation was used to estimate the degree of clustering within herds, cows, and quarters (Dohoo et al., 2009). Next, the simulation method was used to provide a comparison, and a range of values was obtained by varying the number of quarters infected with the pathogen in question at the previous sampling as well as the herd prevalence of that pathogen. The simulation method applies a range of predictor values to the final multilevel model and calculates exact ICC dependent on these values (Vigre et al., 2004). For the ICC estimates reported below, average values of continuous predictors were selected and reference values were used for categorical predictors (Table 1), except for the number of quarters previously infected with the pathogen of interest and the herd prevalence of that pathogen, which were varied in the calculations. Values within cow and within quarter were computed using the methods of Vigre et al. (2004, Appendix A), although the addition of a third level of variance was included, as these were 4-level models. Simulations were run using estimates from the summation models with herd-level predictors. Analyses were carried out using Stata/IC 12.0 (StataCorp, College Station, TX).

\section{RESULTS AND DISCUSSION}

These analyses sought to evaluate interdependence (via estimation of intraclass correlations at the herd, cow, and quarter level) as well as investigate the associations between salient herd-, cow-, and quarter-level predictors and the occurrence of NIMI in individual quarters for both major and minor pathogens. Longitudinal data such as those detailed here can assist in revealing causal relationships, as time series is clearly defined and a clearer picture of the progression of disease can be seen as a particular quarter or cow is followed over time. These analyses, therefore, represent factors associated with the incidence of NIMI, which is different from previous analyses that have mostly examined factors relating to prevalence. The amount of variation at the quarter, cow, and herd level can also be accounted for, and this can provide information about the levels at which NIMI cluster in the dairy operation. 
Table 1. Odd ratios of acquiring a new IMI (NIMI) with the pathogen of interest from multilevel logistic models, including $95 \%$ confidence intervals ${ }^{1}$

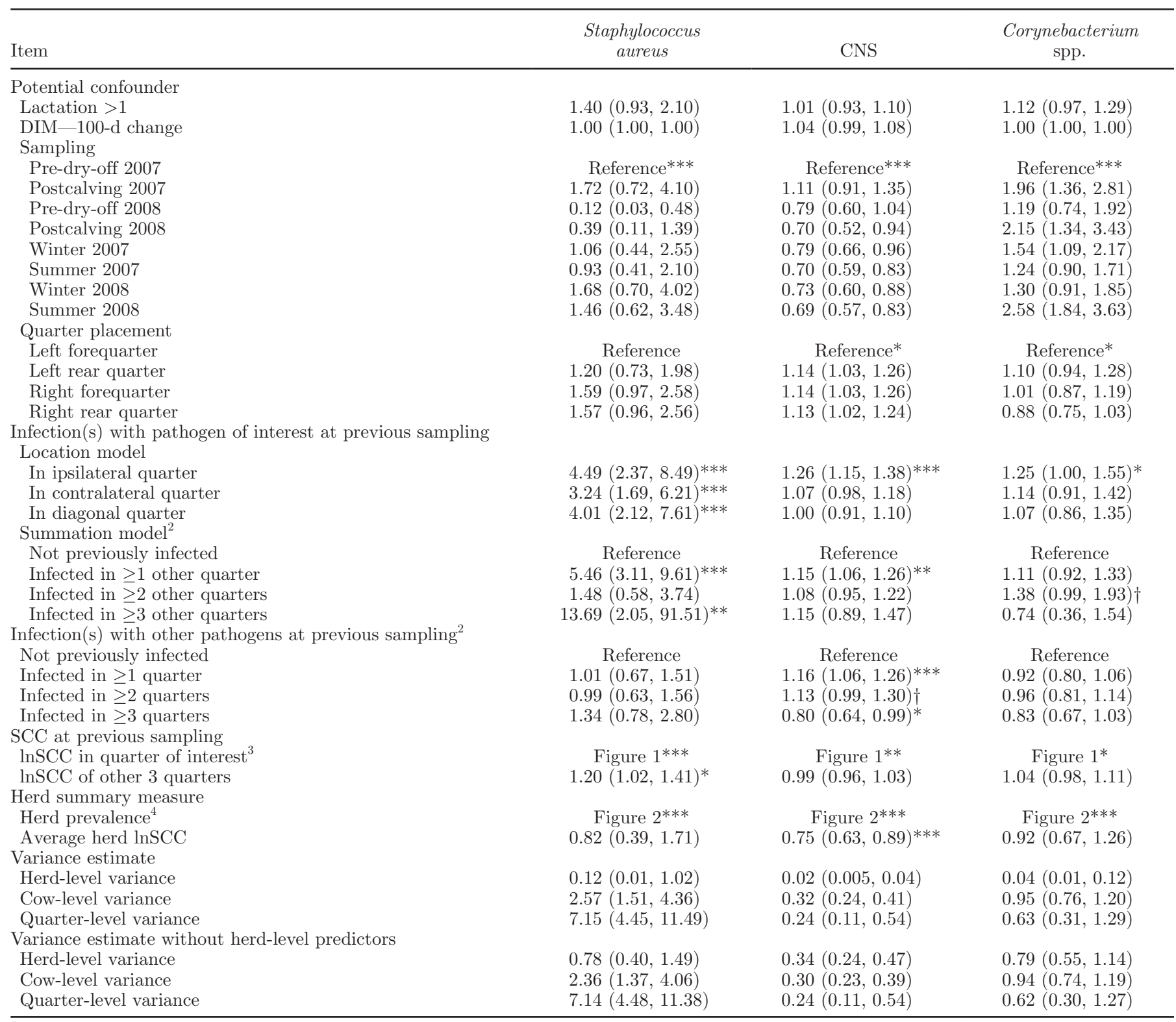

${ }^{1}$ Odds ratios and confidence intervals presented here for predictors common to both location and summation models are derived from the location model with herd-level predictors included.

${ }^{2}$ Number of quarters infected was modeled using hierarchical variables, so coefficients and $P$-values given represent differences from one level to another, not differences compared with the reference value.

${ }^{3} \operatorname{lnSCC}=$ natural log of the SCC included as quadratic and cubic terms based on fractional polynomial evaluations.

${ }^{4}$ Herd prevalence included as square root term based on fractional polynomial evaluations.

$\dagger P \leq 0.10 ;{ }^{*} P \leq 0.05 ;{ }^{* *} P \leq 0.01 ;{ }^{* * *} P \leq 0.001$

\section{Data}

A data set containing 115,162 quarter-level samplings was initially investigated. This data set was made up of 28,928 sets of samples; however, 539 sets of samples contained fewer than 4 samples (i.e., were missing a sample from 1 of a cow's 4 quarters). These were excluded from the analysis, leaving 113,556 samples (28,389 complete sets). Of the samples remaining, 16,266 were contaminated. Only records where none of the cow's quarters were contaminated in the previous sampling were used in these analyses (18,443 complete sets).

Of the samples available for use in the multilevel models, 5,960 and 4,732 were taken from cows before 
dry-off in 2007 and 2008, respectively; 4,724 and 3,840 were taken from cows postcalving in 2007 and 2008, respectively; 10,592 and 9,292 were from the winter 2007 and 2008 lactational sampling periods, respectively; and 24,972 and 9,660 were from the summer, 2007 and 2008 sampling periods, respectively. Three hundred seventeen Staph. aureus NIMI, 4,192 CNS NIMI, and 1,631 Corynebacterium spp. NIMI were included in these data. The geometric mean of SCC at the previous sampling for the quarter being evaluated was 33,000 cells $/ \mathrm{mL}$ (25th percentile, median, and 75 th percentiles $=11,000,22,000$, and 81,000, respectively). The geometric mean of SCC of the other 3 quarters at the previous sampling was $36,500(13,500,27,000$, and 74,000$)$. The mean herd prevalence estimated using samples taken for Staph. aureus was 0.03 (0.01, 0.02, and 0.04), for CNS was 0.21 (0.15, 0.19, and 0.27), and for Corynebacterium spp. was 0.06 (0.02, 0.04, and 0.06). The mean herd SCC estimated using the samples taken was $39,000(31,000,37,500$, and 48,500).

\section{Multilevel Logistic Regression Models}

Odds ratios (OR) and their confidence intervals for the predictors in each of the models are given in Table 1. Odds ratios greater than 1.0 indicate an association with increased risk of acquiring an NIMI, whereas OR less than 1.0 indicate association with protection against a NIMI. Although many predictors were considered in these models and some trends were evident, statistical significance was not achieved for all the predictors, often due to a small number of NIMI in the data set (especially for Staph. aureus). HosmerLemeshow goodness-of-fit tests were used to assess the fit of multivariable models without random effects included, and residual plots were evaluated. The $P$-values for goodness of fit ranged from $P=0.29$ to 0.98 and no more than $5 \%$ of residual points were found to be greater than 2 or less than -2 , except for CNS models where more moderately large residuals $(2-4)$ were seen. Model receiver operating characteristic curves were evaluated and gave an area under the curve of 0.7 or greater, indicating moderate predictive ability of the models.

Potential Confounders. Parity was not a significant predictor in any of the models. Polynomial representations of DIM were evaluated for the pathogens of interest, with the majority identified as linearly related to the outcome. In the interest of parsimony, a linear representation was applied, and DIM was never a statistically significant predictor-its coefficient was always very close to the value for no effect $(\mathrm{OR}=1)$. The sampling period in which the sample was taken (e.g., dry cow sample taken in 2007; lactating cow sample taken in summer 2008) was also included as a categorical predictor. Pairwise comparisons were conducted to investigate and summarize the differences in risk of NIMI seen among the different sampling periods. No obvious trends were seen between samples taken in one sampling period versus another, although the sampling period variables were significant as a whole, accounting for the cross-classification of cows by sampling period.

Specific Quarters. The quarter from which the sample was taken was included in the model as a categorical predictor. A difference in the risk for NIMI was sometimes seen between quarters from which a sample was taken (overall $P=0.19$ for Staph. aureus, 0.03 for CNS, and 0.05 for Corynebacterium spp.). When a Bonferroni adjustment to account for the 6 comparisons that were made between quarters within each pathogen was applied, however, only the relationship between the left rear and right rear quarters in the Corynebacterium spp. model was statistically significant (greater risk was seen in the left rear quarter; Bonferroni-adjusted $P=$ 0.04). Overall, a trend was observed for right quarters to have a higher risk of acquiring a Staph. aureus NIMI than left quarters. The left front quarter also seemed to have the lowest risk of acquiring a CNS NIMI (Table 1).

Some researchers have identified increased infection in specific quarters, namely more infection in hindquarters than forequarters (Batra et al., 1977; Adkinson et al., 1993; Barkema et al., 1997; Berry and Meaney, 2006; Parker et al., 2007), although others have not found differences between numbers or rates of infection in fore- and hindquarters (Honkanen-Buzalski et al., 1984; Zadoks et al., 2001b; Berry et al., 2003) or have found increased IMI in forequarters (Hillerton et al., 1995; Zadoks et al., 2001b). Disagreement in the literature also exists as to the likelihood of infection on different sides of a cow's udder, with Barkema et al. (1997) and Zadoks et al. (2001b) finding more infections occurring in right quarters than left quarters, and others finding no difference between the udder halves (Smith and Coetzee, 1978; Adkinson et al., 1993; Schepers et al., 1997; Berry et al., 2003; Robert et al., 2006). Other studies have identified more infection in certain pairs of quarters: Robert et al. (2006) found more NIMI in front/rear pairs of quarters than in right/ left pairs, whereas Barkema et al. (1997) and Berry and Meaney (2006) found more infections in both right or both left pairs of quarters and fewer in quarters located diagonally across from one another. When comparing only first cases of clinical mastitis in heifers, Adkinson et al. (1993) found no difference in the number of clinical mastitis cases in hind-, fore-, right, or left quarters.

Susceptibility. A tally of the number of quarters with IMI caused by other pathogens in the previous sampling (a type of susceptibility parameter) was in- 
cluded as a hierarchical predictor with 4 levels: no previous infection, 1 or more other quarters also infected, 2 or more quarters also infected, and 3 or more quarters also infected. A hierarchical term for 4 quarters also infected was not significant in any models, so, in the interest of parsimony, it was not retained. Infection with other pathogens had little effect (no statistical significance) in models for Staph. aureus or Corynebacterium spp., whereas infection with other pathogens showed some evidence of changing the risk for NIMI with CNS. Having 1 or more quarters infected with a pathogen other than CNS increased the risk of acquiring an NIMI with CNS $(\mathrm{OR}=1.16 ; P=0.001)$, and this risk was further increased by having 2 or more quarters infected with another pathogen $(\mathrm{OR}=1.13$, compared with having 1 or more quarters infected; $P=$ 0.08). Having 3 or more quarters infected with another pathogen, however, appeared to decrease the risk of acquiring an NIMI with CNS (OR $=0.80$, compared with having 2 or more quarters infected; $P=0.04$ ), although the risk was still increased over having no quarters infected $(\mathrm{OR}=1.05)$. It makes intuitive sense that more susceptible quarters would be more prone to acquiring NIMI, although the protective effect of infection with other pathogens in 3 or more quarters is less obvious. The fact that this relationship was not seen for the pathogens other than CNS may be a function of power, as many more NIMI in these data were caused by CNS than the other pathogens. Alternatively, this may have resulted from CNS comprising most of the "other" infections in the Staph. aureus and Corynebacterium spp. data sets. In the CNS data set, these "other" infections were mainly Corynebacterium spp. and major pathogens, which might be exerting some form of competition on the acquisition of NIMI (particularly with CNS that might be residing on the cow as commensal organisms) if they occur in overwhelming numbers (3 or more quarters infected) within a cow.

Previous Infection with Pathogen of Interest. The location models showed that having an infection with the pathogen of interest in the quarter ipsilateral to the quarter of interest at the previous sampling always significantly increased the risk of acquiring an NIMI (Table 1). Having an infection with Staph. aureus in either the contralateral or diagonal quarter to the quarter of interest also always significantly increased the risk of acquiring an NIMI with Staph. aureus, although this did not hold true for the other pathogens. Adkinson et al. (1993) report measurements of the relative distances between teat ends of a cow's 4 quarters, with the teat ends of the rear quarters located in closest proximity to one another (contralateral in the rear), followed by those of the front and rear teats on the same side of the cow (ipsilateral), then the front teats (contralateral in the front) and, furthest apart, teats positioned diagonally to one another. These researchers found the frequency of clinical mastitis in their study in pairs of quarters to follow this distribution, and also found that both rear quarters were more likely than expected to both be infected, attributing these results to the physical proximity of teat ends. Although front and rear contralateral quarters were not analyzed separately in these analyses, the fact that ipsilateral quarters had a higher risk of NIMI when 1 quarter was already infected does lend credence to the physical proximity hypothesis. A study by Robert et al. (2006), however, did not identify localization of IMI in pairs of quarters relative to teat distance.

Similarly, the summation models revealed that having an infection with the pathogen in question in 1 or more quarters on the previous sampling significantly increased the risk of a NIMI for Staph. aureus and CNS (Table 1). Having a Corynebacterium spp. infection in 2 or more quarters did significantly increase the risk of a NIMI with Corynebacterium spp., however, over that of an infection in 1 or more quarters. For Staph. aureus, the effect of an infection in 2 or more quarters did increase risk (although this was not significantly different from having an infection in 1 or more quarters), whereas an infection in 3 or more quarters raised the risk of acquiring an NIMI substantially (and significantly; Table 1).

Considering the contagious nature of Staph. aureus as well as some species of CNS, these results are not surprising. Zadoks et al. (2001b) also report that the rate of IMI with major pathogens such as Staph. aureus and Strep. uberis is increased in quarters that are exposed to quarters infected with these pathogens (respectively) in the same cow, even with inclusion of cow-level clustering and other predictors related to susceptibility. These studies suggest, therefore, that within-cow transmission does occur for both of these pathogens. The effect seen here was statistically significant for Corynebacterium spp. when 2 or more quarters were infected. This may be because this pathogen is a commensal skin organism that is often present on the cow's teat ends, and as such may be an opportunistic pathogen that is less dependent on actual IMI to multiply and be available to cause an infection in a quarter.

Physical proximity is not the only explanation for exchange of organisms between the quarters of a cow, although it has been hypothesized to explain interdependence during the dry period, when few other management factors (e.g., milking and teat dipping) except physical contact between the teats might be present. During lactation, however, when all the sets of samples investigated in this study were collected, cross-contamination may occur via repeated use of cloths for wiping 
different teats of the same cow, transfer of pathogens in the dip cup used between teats and between cows, or milking machine contamination and passage of infection from one cow to the next. In fact, in studies conducted over the dry period by Berry et al. (2003), very few NIMI occurred in cows with other quarters infected with Staph. aureus, indicating that the risk from within the cow may be greater during lactation than over the dry period.

SCC Parameters. The relationships between the SCC in the same quarter at the previous sampling for models including herd-level predictors are shown in Figure 1. Graphs were very similar for models not including herd-level predictors, although the steepness of the curves were slightly increased (data not shown). In Staph. aureus models, the OR of a quarter developing an NIMI stayed relatively stable until the SCC at the previous sample approached 300,000 cells/mL (Figure 1). For CNS, it can be seen that as SCC increases from 0 to approximately 37,000 cells $/ \mathrm{mL}$, the risk of acquiring a CNS NIMI also increases (Figure 1). No further increase in risk exists until SCC rises beyond approximately 2,000,000 cells/mL, when the risk of an NIMI increases dramatically.

Previous work has shown that $\operatorname{lnSCC}$ of the sample before diagnosis of a major pathogen NIMI was always significantly associated with increased risk of acquiring a major pathogen NIMI (Reyher et al., 2012). A similar relationship was found here with Staph. aureus and CNS, and again it is postulated that this association is an effect of the low sensitivity for pathogens by bacteriological examination. Dohoo et al. (2011b) have shown the sensitivity of bacteriological examination for

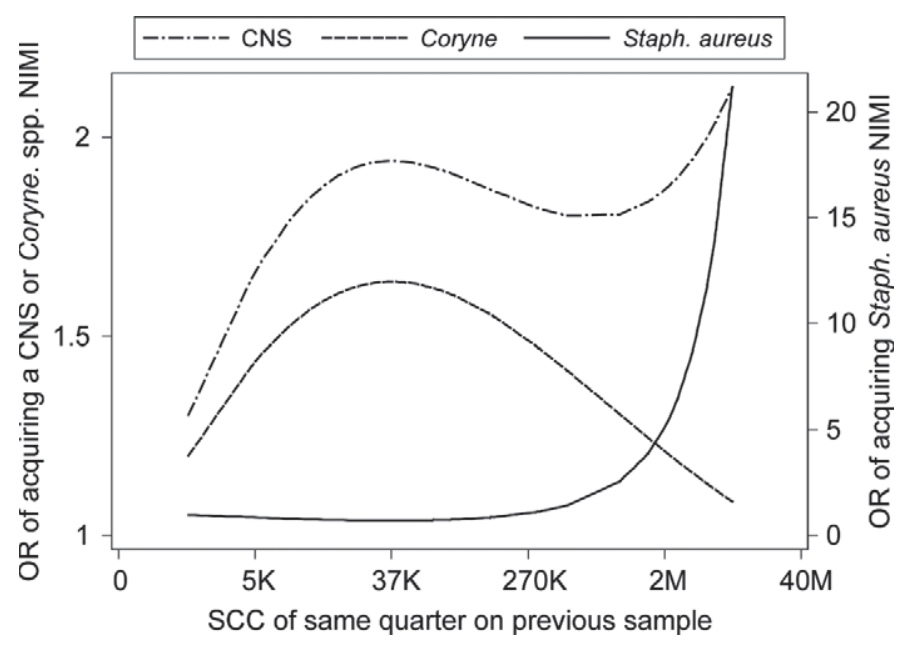

Figure 1. Relationship between the odds ratio (OR) of acquiring a new IMI (NIMI) with Staphylococcus aureus, CNS, and Corynebacterium spp. (Coryne) and SCC in the same quarter at the previous sampling from the location model with herd-level predictors.
Staph. aureus, CNS, and Corynebacterium spp. to be $90.4,56.2$, and $78.2 \%$, respectively, with the definitions used here. Thus, it is likely that some infections will be missed (up to $10 \%$ for Staph. aureus and many more for the other pathogens), meaning that part of the positive association with risk seen here is likely a result of diagnosing an NIMI after it had already occurred.

Staphylococcus aureus is known to cause significant increases in SCC (Djabri et al., 2002), so it is not surprising that a strongly significant association of $\operatorname{lnSCC}$ with the risk of acquiring an NIMI with this pathogen exists at higher levels of SCC, reflecting the fact that inflammation accompanying infection existed, although bacteriological evidence of the NIMI was not yet identified (Figure 1). Coagulase-negative staphylococci cause a more moderate increase in SCC (Djabri et al., 2002), although the majority of species present in this data set can cause an increase in SCC similar to that seen for Staph. aureus (Supré et al., 2011). The effect seen in these analyses, however, is not as dramatic as that seen for Staph. aureus (Figure 1). Both the lower sensitivity for diagnosis of a CNS infection and the lower SCC caused by this group of pathogens may have a moderating effect on the association between increasing SCC and an increased risk of NIMI, although a positive relationship does exist. In models not accounting for the average herd SCC, the effect seen is more distinct (the scale for odds ratio is much higher), but the curve maintains its shape.

For Corynebacterium spp., although the risk of an NIMI rises as the cell count of the quarter on the previous sample rises from 0 to approximately 37,000 cells/ $\mathrm{mL}$, this risk then decreases as the cell count continues to increase (Figure 1). Some studies have shown that Corynebacterium spp. are inhibited by infection with major pathogens such as Staph. aureus and Strep. uberis in the udder (Honkanen-Buzalski, et al., 1984). As Corynebacterium spp. tend to cause less inflammation and only a moderate rise in SCC (Djabri et al., 2002), the effect demonstrated in Figure 1 may be a result of these infections being inhibited by the presence of other pathogens that are causing a substantial increase in SCC.

Although these graphs were constructed from the fractional polynomial transformations that seemed to best represent the relationship of $\operatorname{lnSCC}$ with the outcome, their shape may not be an exact representation of the effect of SCC in the quarter at the previous sampling. Confidence intervals in the graphs were also quite wide, especially at the ends (data not shown). Overall, including herd-level predictors decreased the scale of the increase of risk as these predictors account for a portion of the effect (by including it in the herdlevel SCC predictor). 
The $\operatorname{lnSCC}$ of the other 3 quarters on the previous sampling did not show a significant effect on the risk of acquiring an NIMI for any of the pathogens except Staph. aureus, where the odds or acquiring an NIMI increased as the $\operatorname{lnSCC}$ of the other 3 quarters rose (Table 1). This result is likely illustrating the contagious nature of Staph. aureus as well as its ability to cause inflammation and resultant high SCC in the udder. Cows with a high average SCC in the other 3 quarters at the previous sampling were likely to have been infected with Staph. aureus in 1 of those quarters, and this infection was more likely to spread to the quarter in question (see above).

Cow- and Herd-Level Predictors. Cow-level and herd-level predictors were used to model the variation of the prevalence of the individual pathogens and lnSCC both between cows and between herds. Because of their close relationship with the effects being investigated (e.g., infection in the ipsilateral, contralateral, or diagonal quarters), the predictor for the prevalence of pathogen between cows disrupted these coefficients, so they were not retained in final models. Herd prevalence was investigated using fractional polynomials and was found to be best represented by a square root term that retained significance in multivariable models. In all models, as the herd-level prevalence of the pathogen of interest increased, the odds ratio of acquiring an NIMI also increased (Figure 2). This increase was greatest for Staph. aureus over the small range of herd prevalence for this pathogen, and most slight for CNS over a much wider range of prevalence (Figure 2). This association with increasing risk of acquiring an NIMI is not surprising, as all these pathogens exhibit some contagious properties. Having more cows in a herd infected with these pathogens, therefore, would serve to increase the infectious pressure on quarters, making it more likely for them to acquire an NIMI.

The average lnSCC of herds had a linear relationship with the outcome in the majority of univariable models, so was represented in this way in the multivariable models. After accounting for herd prevalence in the multivariable models, average herd $\operatorname{lnSCC}$ was seen to be significantly associated with decreased risk of NIMI for CNS (Table 1). A closer look at the data revealed that CNS prevalence had a quadratic relationship with herd SCC: although increasing initially, as prevalence of CNS in a herd rose, average SCC began to fall once CNS prevalence exceeded 20\%. This is interesting, as Supré et al. (2011) have shown that the species of CNS that made up the majority of isolates in this data set often cause increases in cell count on par with those caused by Staph. aureus and that distributions of CNS may be herd specific. Including the prevalence of this pathogen in the multivariable models should account for its effect on the outcome, meaning that the effect of SCC seen here must be caused by other factors. The immune competency of the cows in that herd, average age of cows in the herd, a higher prevalence of infections with major pathogens, or other factors in the herd not accounted for in these models might be having an impact. These factors, then, seem to be playing some protective role against a quarter acquiring an NIMI with CNS. Again, the fact that no association was seen with the other pathogens may be a function of power or a difference in the protective effects on the individual pathogens examined.

\section{Variance Factors and ICC}

Initially, models without any predictors for several pathogens were fit in efforts to estimate the overall clustering of IMI and NIMI in herds, cows, and quarters. Although some of these models produced estimates for all levels of clustering, most of them did not converge, so estimates provided here are from the multivariable, multilevel models. The random effects in the multilevel models were added at the herd level to account for clustering of cows within herds, at the cow level to account for clustering of quarters within cows, and at the quarter level to account for clustering of samples within quarters (repeated measures). For Staph. aureus, the variance at quarter level was greatest, followed by variance at the cow and herd levels (Table 1). Most of the unexplained variation in the acquisition of new Staph. aureus NIMI, therefore, is within individual

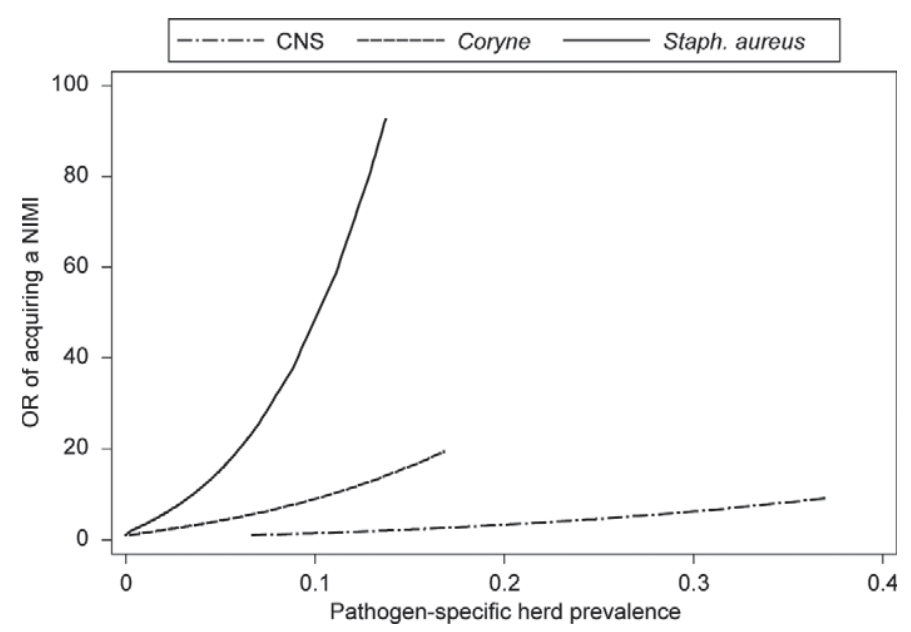

Figure 2. Relationship between the odds ratio (OR) of acquiring a new IMI (NIMI) with Staphylococcus aureus, CNS, and Corynebacterium spp. (Coryne) and the pathogen-specific herd prevalence. 
Table 2. Intraclass correlations for new IMI (NIMI) within herd, within cow, and within quarter for pathogens investigated (estimates calculated using the latent variable approach)

\begin{tabular}{lccc}
\hline Intraclass correlation & $\begin{array}{c}\text { Staphylococcus } \\
\text { aureus }\end{array}$ & CNS & $\begin{array}{c}\text { Corynebacterium } \\
\text { spp. }\end{array}$ \\
\hline Location model-without herd-level predictors & & & \\
$\quad$ Within herd & 0.06 & 0.08 & 0.14 \\
Within cow & 0.23 & 0.15 & 0.31 \\
Within quarter & 0.76 & 0.21 & 0.42 \\
Summation model-with herd-level predictors & 0.2 & 0.09 & 0.2 \\
$\quad$ Within cow & 0.75 & 0.15 & 0.33 \\
Within quarter & &
\end{tabular}

quarters. Using both the latent variable and simulation approaches, the ICC for samples in the same quarter was very high, especially as compared with that of the other pathogens (Table 2 and Figure 3). Intraclass correlation coefficients within quarters and within cows varied considerably depending on how many quarters in that cow were previously infected with Staph. aureus, and always increased as the herd prevalence of Staph. aureus increased (Figures 3 and 4). The ICC for Staph. aureus NIMI in samples of different cows in the same herd was the lowest of the 3 pathogens investigated (Table 2).

For CNS, variance at all 3 levels was similar and fairly small, with slightly more variation resting at the herd level than cow or quarter levels (Table 1). The ICC for samples in the same quarter was the lowest of the 3 pathogens considered (Table 2), and did not vary greatly as the number of quarters previously infected

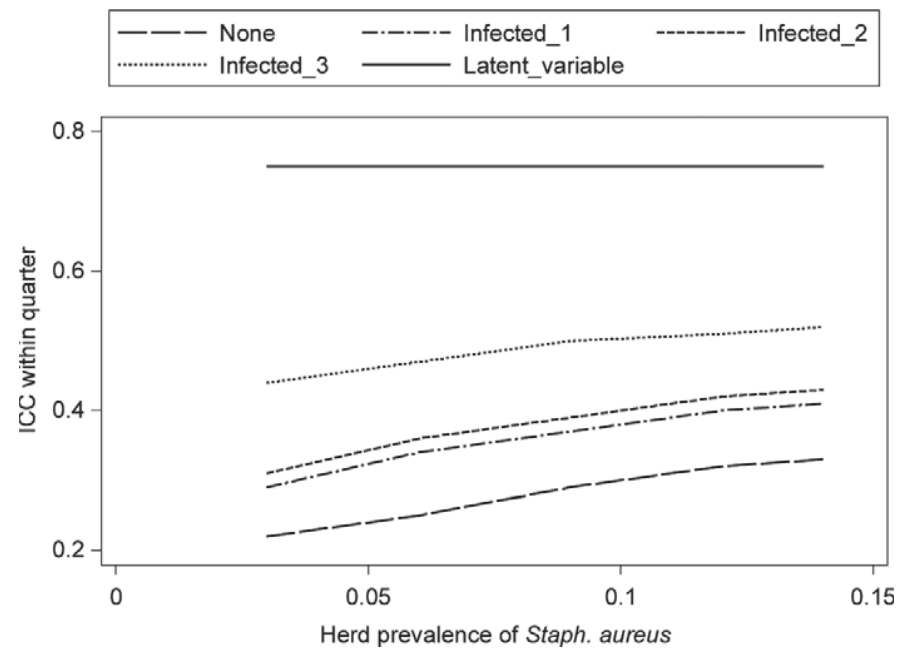

Figure 3. Relationship between simulated within-quarter intraclass correlation coefficient (ICC) values and herd-level prevalence of Staphylococcus aureus for different levels of previous infection with Staph. aureus. None $=$ no quarters previously infected; Infected_1 $=$ $1+$ quarters previously infected; Infected_2 $=2+$ quarters previously infected; Infected_3 = 3+ quarters previously infected; Latent_variable = ICC calculated using latent variable method. with CNS increased (Figure 5). The ICC for samples from different quarters of the same cow was also lowest for CNS (Table 2) and similarly did not vary as the number of previously infected quarters increased.

Corynebacterium spp. had moderate variance factors, with cow-level variance being greatest (Table 1). Similar to CNS, the within-quarter correlation did not vary greatly when different numbers of quarters had been previously infected with Corynebacterium spp. (data not shown). The ICC for samples from different quarters from the same cow were greatest for this pathogen compared with the others (Table 2) and the ICC for samples of different cows in the same herd was also highest for this pathogen (Table 2).

Intraclass correlation coefficients calculated using the simulation method were always much lower than those calculated using the latent variable approach (Figures 3 and 5 as well as data not shown), with the excep-

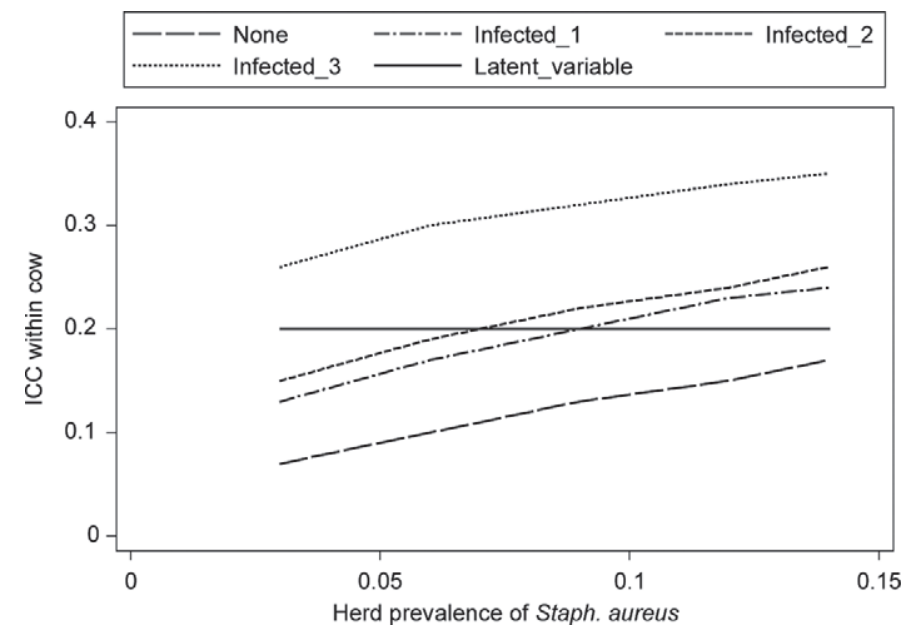

Figure 4. Relationship between simulated within-cow intraclass correlation coefficient (ICC) values and herd-level prevalence of Staphylococcus aureus for different levels of previous infection with Staph. aureus. None $=$ no quarters previously infected; Infected_1 = $1+$ quarters previously infected; Infected_2 $=2+$ quarters previously infected; Infected_3 = 3+ quarters previously infected; Latent_variable $=$ ICC calculated using latent variable method . 


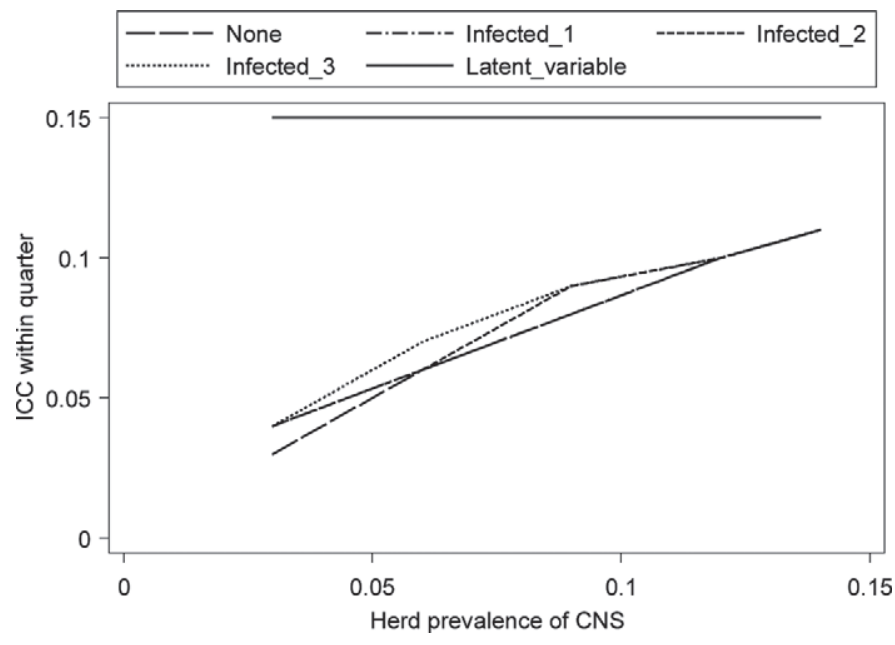

Figure 5. Relationship between simulated within-quarter intraclass correlation coefficient (ICC) values and herd-level prevalence of CNS for different levels of previous infection with CNS. None $=$ no quarters previously infected; Infected_1 $=1+$ quarters previously infected; Infected_2 $=2+$ quarters previously infected; Infected_3 $=3+$ quarters previously infected; Latent_variable $=$ ICC calculated using latent variable method.

tion of within-cow ICC for Staph. aureus (Figure 4). As herd prevalence of a certain pathogen increased, the ICC within quarter and within cow was always seen to increase (Figures 3, 4, and 5).

The ICC reported here are expected to differ from those reported in other studies for several reasons. First, most of the other published literature examines prevalence of IMI instead of incidence of NIMI, which is perhaps of greater interest, as it directly pertains to management of mastitis. Second, variance of a sample is population specific, so these variances can only be compared within a population and not across populations. The variances reported here were, however, very similar to those calculated in other studies using these data (S. Dufour, CBMRN National Cohort of Dairy Farms, Saint-Hyacinthe, QC, Canada, personal communication). Third, the type of model chosen will influence the variance parameters, with the fixed effects included in these models accounting for some of the variation that might be attributed to cow or herd-level clustering in a null model, for instance. Still, the order of ICC should remain fairly similar among pathogens, indicating the levels at which pathogens cluster. In this study, ICC for samples from cows in the same herd was greatest for NIMI caused by Corynebacterium spp., followed by CNS and Staph. aureus. The same order was found by Barkema et al. (1997), who considered IMI of these pathogens, among others. These authors also found Corynebacterium spp. to have the highest ICC for samples within the same cow, although, in contrast to the study presented here, more clustering within cows was identified for CNS than for Staph. aureus. In agreement with this study, however, Berry and Meaney (2006) found a greater ICC within cows for Staph. aureus than for CNS.

Herd-Level Clustering. Herd-level variance was greatest only for CNS, where all variance parameters were comparable, although it was substantial for the other pathogens as well. Again, this may have to do with the contagiousness of the pathogens investigated here, as herd prevalence was also shown to have a significant effect on the acquisition of NIMI with each of these pathogens - the risk of NIMI increased as herd prevalence increased. Most studies have found herd-level clustering to be much less substantial than cow-level clustering (Barkema et al., 1997; Parker et al., 2008; Piepers et al., 2011). As most of the herds included in this data collection practiced modern and progressive management (although to differing degrees), large differences between herds may not have existed as much as they might in a random sample of herds. The fact that herd-level clustering exists to some degree, however, means that producers can do more to address NIMI incidence in their herds and they can make further changes at the herd level to decrease the prevalence of mastitis experienced on farm. This was illustrated especially by the substantial increase in risk of NIMI that results from an increase in the herd-level prevalence of these pathogens. The exponential increase in risk shown in Figure 2 may suggest that it is worth the extra effort for producers to decrease their herd prevalence, especially of Staph. aureus, and thereby reduce the risk of quarters acquiring an NIMI with this pathogen. By reducing the prevalence of Staph. aureus from 0.1 to 0.05 , for instance, the OR of acquiring an NIMI is lowered more than 3 fold. Management practices that address IMI at the herd level, therefore, play an important role in overall mastitis management.

Cow-Level Clustering. Most of the unexplained variation in NIMI occurrence for Corynebacterium spp. occurred at the cow level (Table 1). Significant cowlevel clustering has also been found by several authors previously (Grootenhuis, 1975; Smith and Coetzee, 1978; Rainard and Poutrel, 1984; Adkinson et al., 1993: Barkema et al., 1997; Schepers et al., 1997; Berry et al., 2003; Zadoks et al., 2003; Berry and Meaney, 2006; Robert et al., 2006; Parker et al., 2008; Piepers et al., 2011). It might be assumed that predominately contagious pathogens (a category into which Corynebacterium spp. and Staph. aureus would certainly fall) would be more likely to cluster within cows as they pass back and forth between quarters, whereas environmental organisms would be less likely to show such clustering. 
Parker et al. (2007), in fact, showed minimal cow-level clustering for Strep. uberis, although some strains of this pathogen are capable of being transmitted from cow to cow (Zadoks et al., 2003). Cow-level clustering may potentially be less important in the dry period than during lactation because pathogens are not being transferred by milking equipment during this time, although clustering within cows was identified by Robert et al. (2006) and Berry et al. (2003). Because this within-cow transmission of mastitis pathogens certainly occurs, adequate treatment of these infections should be considered to prevent further infections. Although these analyses would suggest that decreasing extant IMI will serve to prevent NIMI from occurring in a cow, the increased risk caused by these IMI must also be balanced with the economics of treatment (e.g., initiating treatment during lactation or waiting for the dry period). No economic analyses were included in this work, but further evaluations could join these results with economic data to provide further insight into the benefits of IMI treatment. Similarly, this work shows that some cows are liable to contract more new infections than others, not just that some just tend to carry a higher infection load (have more chronic infections). Identifying and removing susceptible cows from the herd early might also enhance efforts to control mastitis.

Quarter-Level Clustering. In the study presented here, quarter-level clustering was demonstrated most remarkably for Staph. aureus. Although it did exist for all the pathogens considered, the vast majority of the unexplained variation was at the quarter level for this pathogen. This result indicates that quarters that have had previous NIMI with Staph. aureus are very likely to be reinfected with Staph. aureus; to a lesser degree, the same was true for CNS and Corynebacterium spp. Zadoks et al. (2001b) also identified quarter-level clustering, showing that quarters recovered from IMI with Staph. aureus and Strep. uberis were more likely to be infected with either of those pathogens than were quarters that had been shown to be free from IMI with those pathogens. Other papers have also demonstrated quarter-level clustering (Myllys, 1995; Zadoks et al., 2001a), although it is not identified in every study (Berry et al., 2003; Parker et al., 2007). Zadoks et al. (2001a) found that quarters that had recovered from Strep. uberis infection had an incidence rate of occurrence of the same pathogen that was 7.5 times as high as that found in quarters that had been free from Strep. uberis infection $(P<0.001)$. Zadoks et al. (2001a) further showed the incidence rate of Strep. uberis to be higher in quarters infected with other pathogens than uninfected quarters, although the result was not statistically significant $(P>0.20)$. Myllys (1995) also found that quarters of heifers that were infected precalving were more likely to be diagnosed with NIMI after calving than were previously uninfected quarters, whereas quarters with IMI precalving in the study by Parker et al. (2007) did not have a greater risk of NIMI after calving. Certain quarters may be susceptible for several reasons, be they anatomical (e.g., teat-end lesions, short and wide teat canals, or large teat-end openings), immunological (failure of leukocytes to respond in adequate numbers or functionality), or as the result of damage throughout the cow's lactation (Green et al., 2002, 2005). Damage caused by a virulent pathogen such as Staph. aureus may also predispose quarters to reinfection.

Because the majority of the variance was identified at the quarter level for Staph. aureus, producers should focus their control of this pathogen specifically on preventing individual quarters from becoming infected. Management practices such as pre- and postmilking teat disinfection, correct milking machine management, wearing gloves, and maintaining good teat-end condition can prevent acquisition of NIMI with Staph. aureus (Dufour et al., 2012a). The work presented here shows that management of this pathogen at the quarter level is likely to have the greatest impact on decreasing NIMI occurrence.

Another possible explanation for the large amounts of quarter clustering would be persistence of infection and diagnosis of an NIMI after an intermediate false negative diagnosis. Because the definition of an NIMI meant that it needed to occur after 1 negative sample, the estimates for quarter-level clustering presented here are all derived from the summer of 2007 sampling period, where samples were collected once per week for 7 wk (no other sampling series permitted diagnosis of more than 1 NIMI within a period). If, for instance, a chronic infection existed over $3 \mathrm{wk}$, but the quarter sample taken in the middle week was falsely negative for the pathogen in question, 2 NIMI would have been identified, adding to the estimates of quarter-level clustering. Because these results were based on only 1 sampling period, they may not be widely applicable. All the pathogens investigated in this study demonstrate some level of chronicity, so this effect of low Se of bacteriological culture may be contributing to the findings of quarter-level clustering. Staphylococcus aureus may also be shed cyclically and, therefore, missed by bacteriological culture, although a recent study has reviewed cyclical shedding patterns and supports the use of a single sample as fairly accurate for diagnosis with Staph. aureus (Walker et al., 2011). Molecular typing methods to identify the strains of pathogens causing IMI and NIMI in these quarters might be used to further investigate the amount of persistence of IMI in 
quarters that may be contributing to these estimates of quarter clustering.

Estimation of ICC Values. Two different methods were used to calculate the ICC reported here. Calculation of ICC using the latent variable approach assumes that a certain threshold of disease exists, above which the disease is diagnosed. Perhaps this logic cannot be applied directly to IMI, as it is a truly binary outcome, especially with some of the definitions used here (where $100 \mathrm{cfu} / \mathrm{mL}$, or presence $=1$ colony from the $0.01 \mathrm{~mL}$ of milk cultured, was considered diagnostic). Variance at the sample level also depends on the probability of an NIMI, so although the latent variable approach uses a fixed error variance at this level, in reality, no single estimate of this variance truly exists. The latent variable approach, therefore, gives only an approximation of the true ICC, and one that tends to be larger than the true value (Vigre et al., 2004; Dohoo et al., 2009). The simulation method, on the other hand, calculates exact ICC values, but these are dependent on the values of the predictors in the final model. If maximum values of continuous predictors and categories of categorical predictors with the largest coefficients had been chosen in simulations, greater values of ICC would have been obtained, and these values may have approached the values given by the latent variable calculations.

It was of interest to see the difference that a change in the status of the cow at the previous sampling with respect to the pathogen in question would have on the amount of clustering seen within quarters and within cows. This difference was only substantial for Staph. aureus, with the ICC rising as the number of previously infected quarters increased (Figures 3 and 4). This is perhaps not surprising given the contagious and potentially chronic nature of Staph. aureus infectionsquarters of cows having previous infections would be more likely to acquire an NIMI, and potentially more than 1 (hence the clustering of NIMI within a quarter), as Staph. aureus would be resident in that cow and in close proximity to uninfected quarters. Preventing NIMI is therefore, as mentioned previously, of utmost importance for management of this pathogen. This effect was not seen as obviously for CNS or Corynebacterium spp., either within quarter or within cow. It was also interesting to evaluate what effect a change in the herd-level prevalence of these pathogens would have on the amount of clustering seen within quarters and within cows (evaluating within-herd clustering was not feasible, as including the herd-level variables accounted for most of the herd-level variability and decreased the herd-level variance estimates substantially). The ICC within quarters always increased as herd-level prevalence of the pathogen increased (Figures 3 and 5), so management changes to limit NIMI at the herd level should be specifically encouraged.

\section{Definitions and Misclassification Bias}

The definition of IMI used here $(>100 \mathrm{cfu} / \mathrm{mL}$ in a single sample for major pathogens and Corynebacterium spp. and $>200 \mathrm{cfu} / \mathrm{mL}$ in a single sample for CNS) differs from that of previous authors, but is believed it to provide a good balance between Se and Sp (Dohoo et al., 2011b). Maximizing Se for Staph. aureus and Corynebacterium spp., as this definition does, served to identify as many IMI as possible while still achieving a high Sp. A more strict definition of CNS IMI was chosen to prevent false-positive results (increasing Sp from 87 to $95 \%$ ), as these organisms occur on teat skin and, although found in milk samples, may not always be indicative of an IMI. This did reduce the Se of isolating CNS from 81 to $56 \%$, so potentially several CNS infections were not identified. Misclassification bias, which is inherent when using imperfect diagnostic tools such as bacteriology, will affect both estimation of IMI in the population as well as estimation of NIMI as an outcome. As such, its overall effect is difficult to predict. In fact, a recent study by Dufour et al. (2012b) showed that correcting for misclassification bias when a definition of $100 \mathrm{cfu} / \mathrm{mL}$ was used actually decreased the incidence of CNS IMI. In the analyses presented here, it was believed that a more strict definition of CNS was required to prevent identification of an effect based on a falsely positive diagnosis with CNS.

In the data used for these analyses, neither speciation of CNS nor of Corynebacterium spp. was present, which may have limitations. A large number of types of CNS are found in bovine milk, causing a wide range of chronicity and inflammatory effects in the mammary gland (Supré et al., 2011). Speciation of a subset (n $=1,400$ ) of the CNS-positive samples included here has been completed, and 20 different species of CNS were identified. Of these, Staphylococcus chromogenes, Staphylococcus xylosus, and Staphylococcus simulans were found to account for $>75 \%$ of CNS IMI in this subset (Middleton et al., 2010). Coryneform bacteria also comprise several different species and strains. Because these pathogens have different properties, the common practice of grouping them together at the genus level may obscure some of their true activity. For instance, if some species behave in a more contagious fashion, their effect would appear decreased when less contagious species of the same genus were also considered. Hence, it would be ideal to use speciated CNS and Corynebacterium spp. samples in the analyses of these data (Supré et al., 2011). 


\section{CONCLUSIONS}

Most of the previous work concerning clustering has focused on prevalent IMI, but the CBMRN data provide an opportunity to investigate the clustering of NIMI and, therefore, draw conclusions on what may predispose cows to new infections instead of just infection in general. Certainly this is of interest to researchers and producers alike who are searching for ways to decrease the impact of mastitis, especially through the tenet of decreasing new infections. The results of these analyses suggest that efforts to decrease NIMI should occur at all levels (herd, cow, and quarter), and that producers should incorporate aims to maintain a low herd prevalence (particularly of contagious organisms), avoid chronic IMI that can contribute to acquisition of NIMI, and address attributes of individual quarters that may expose them to repeated infection with pathogens.

\section{ACKNOWLEDGMENTS}

This work would not have been possible without the other organizers of the Canadian Bovine Mastitis Research Network (Saint-Hyacinthe, QC, Canada) data collection platform, the National Cohort of Dairy Farms: Herman Barkema, Luc Des Côteaux, Trevor DeVries, Simon Dufour, and Jean-Philippe Roy. Special thanks are extended to the reviewers who offered significant advice for improving the manuscript. This research was financed by the Natural Science and Engineering Research Council (NSERC, Ottawa, ON, Canada); Alberta Milk (Edmonton, AB, Canada); Dairy Farmers of New Brunswick (Sussex, NB, Canada), Nova Scotia (Lower Truro, NS, Canada), Ontario (Mississauga, ON, Canada), and Prince Edward Island (Charlottetown, PE, Canada); Novalait Inc. (Québec, QC, Canada); Dairy Farmers of Canada (Ottawa, ON, Canada); Canadian Dairy Network (Guelph, ON, Canada); Agriculture and Agri-Food Canada (Ottawa, ON, Canada); Public Health Agency of Canada (Ottawa, ON, Canada); Technology PEI Inc. (Charlottetown, PE, Canada); Université de Montréal (Montréal, QC, Canada); and the University of Prince Edward Island (Charlottetown, PE, Canada), through the Canadian Bovine Mastitis Research Network. Personal support comes from the Atlantic Veterinary College (Charlottetown, PE, Canada) DVM Graduate Program Award and NSERC Canada Graduate Scholarship.

\section{REFERENCES}

Adkinson, R. W., K. H. Ingawa, D. C. Blouin, and S. C. Nickerson. 1993. Distribution of clinical mastitis among quarters of the bovine udder. J. Dairy Sci. 76:3453-3459.
Barkema, H. W., Y. H. Schukken, T. J. G. M. Lam, D. T. Galligan, M. L. Beiboer, and A. Brand. 1997. Estimation of interdependence among quarters of the bovine udder with subclinical mastitis and implications for analysis. J. Dairy Sci. 80:1592-1599.

Batra, T. R., B. J. Nonnechke, F. H. Newbould, and R. R. Hacker. 1977. Incidence of clinical mastitis in a herd of Holstein cattle. J. Dairy Sci. 60:1169-1172.

Berry, D. P., and W. J. Meaney. 2006. Interdependence and distribution of subclinical mastitis and intramammary infection among udder quarters in dairy cattle. Prev. Vet. Med. 75:81-91.

Berry, E. A., W. T. Johnston, and J. E. Hillerton. 2003. Prophylactic effects of two selective dry cow strategies accounting for interdependence of quarter. J. Dairy Sci. 86:3912-3919.

Browne, W., S. Subramanian, K. Jones, and H. Goldstein. 2005. Variance partitioning in multilevel logistic models that exhibit overdispersion. J. Royal Stat. Soc. A 168:599-613.

Djabri, B., N. Bareille, F. Beaudeau, and H. Seegers. 2002. Quarter milk somatic cell count in infected dairy cows: A meta-analysis. Vet. Res. 33:335-357.

Dohoo, I., S. Andersen, R. Dingwell, K. Hand, D. Kelton, K. Leslie, Y. Schukken, and S. Godden. 2011a. Diagnosing intramammary infections: Comparison of multiple versus single quarter milk samples for the identification of intramammary infections in lactating dairy cows. J. Dairy Sci. 94:5515-5522.

Dohoo, I. R., S. W. Martin, and H. Stryhn. 2009. Mixed models for discrete data. Pages $583-585$ in Veterinary Epidemiologic Research. 2nd ed. VER Inc., Charlottetown, PEI, Canada.

Dohoo, I. R., J. Smith, S. Andersen, D. F. Kelton, and S. Godden. 2011b. Diagnosing intramammary infections: Evaluations based on a single milk sample. J. Dairy Sci. 94:250-261.

Dohoo, I. R., E. Tillard, H. Stryhn, and B. Faye. 2001. The use of multilevel models to evaluate sources of variation in reproductive performance in dairy cattle in Reunion Island. Prev. Vet. Med. 50:127-144.

Dufour, S., I. R. Dohoo, H. W. Barkema, L. Des Côteaux, T. J. DeVries, K. K. Reyher, J.-P. Roy, and D. T. Scholl. 2012a. Manageable risk factors associated with the lactational incidence, elimination and prevalence of Staphylococcus aureus intramammary infections in dairy cows. J. Dairy Sci. 95:1283-1300.

Dufour, S., I. R. Dohoo, H. W. Barkema, L. Des Côteaux, T. J. DeVries, K. K. Reyher, J.-P. Roy, and D. T. Scholl. 2012b. Coagulase-negative staphylococci intramammary infection epidemiology in dairy cattle and impact of bacteriological culture misclassification. J. Dairy Sci. 95:3110-3124.

Erskine, R. J., and R. J. Eberhart. 1988. Comparison of duplicate and single quarter milk samples for the identification of intramammary infections. J. Dairy Sci. 71:854-856.

Goldstein, H., W. Browne, and J. Rasbash. 2002. Partitioning variation in multilevel models. Underst. Stat. 1:223-231.

Green, M. J., L. E. Green, A. J. Bradley, P. R. Burton, Y. H. Schukken, and G. F. Medley. 2005. Prevalence and associations between bacterial isolates from dry mammary glands of dairy cows. Vet. Rec. 156:71-77.

Green, M. J., L. E. Green, G. F. Medley, Y. H. Schukken, and A. J. Bradley. 2002. Influence of dry period bacterial intramammary infection on clinical mastitis in dairy cows. J. Dairy Sci. 85:25892599 .

Grootenhuis, G. 1975. Mastitis; a survey on the inter-dependence of the quarters of a cow. Tijdschr. Diergeneeskd. 100:745-751.

Hillerton, J. E., M. H. H. Shearn, and J. G. H. West. 1995. Risk factors for summer mastitis. Proc. of 3rd Int. Mastitis Conf. Session 6:88. National Mastitis Reference Center, Bet Dagan, Israel.

Hogan, J. S., R. N. Gonzalez, S. C. Harmon, S. P. Nickerson, J. W. Oliver, J. W. Pankey, and K. L. Smith. 1999. Laboratory Handbook on Bovine Mastitis. 1st ed. National Mastitis Council, Madison, WI.

Honkanen-Buzalski, T., T. K. Griffin, and F. H. Dodd. 1984. Observations on Corynebacterium bovis infection of the bovine mammary gland. I. Natural infection. J. Dairy Res. 51:371-378.

Middleton, J. R., J. Perry, D. T. Scholl, S. Dufour, I. R. Dohoo, C. Calloway, and S. Andersen. 2010. Relationship between coagulase- 
negative staphylococcal species and mammary quarter milk somatic cell count on North American dairy farms. Page 22 in Proc. of Seminar on Coagulase-Negative Staphylococci in the Bovine, Ghent, Belgium. Universiteit Gent, Ghent, Belgium.

Miller, C. C. 1975. Considerations in the evaluation of a mastitis treatment product. Pages 102-109 in Proc. 14th Ann. Meeting. NMC Inc., Verona, WI.

Myllys, V. 1995. Staphylococci in heifer mastitis before and after parturition. J. Dairy Res. 62:51-60.

Parker, K. I., C. Compton, F. M. Anniss, C. Heuer, and S. McDougall. 2008. Quarter-level analysis of subclinical and clinical mastitis in primiparous heifers following the use of a teat sealant or an injectable antibiotic, or both, precalving. J. Dairy Sci. 91:169-181.

Parker, K. I., C. Compton, F. M. Anniss, A. Weir, C. Heuer, and S. McDougall. 2007. Subclinical and clinical mastitis in heifers following the use of a teat sealant precalving. J. Dairy Sci. 90:207-218.

Piepers, S., K. Peeters, G. Opsomer, H. W. Barkema, K. Frankena, and S. De Vliegher. 2011. Pathogen group specific risk factors at herd, heifer and quarter levels for intramammary infections in early lactating dairy heifers. Prev. Vet. Med. 99:91-101.

Rainard, P., and B. Poutrel. 1984. Non-random distribution of udder infections among cows. Evaluation of some contributing factors. Ann. Rech. Vet. 15:119-127.

Reyher, K. K., I. R. Dohoo, D. T. Scholl, and G. P. Keefe. 2012. Evaluation of minor pathogen intramammary infection, susceptibility parameters and somatic cell counts on the development of new intramammary infections with major mastitis pathogens. J. Dairy Sci. 95:3766-3780.

Reyher, K. K., S. Dufour, H. W. Barkema, L. Des Côteaux, T. J. DeVries, I. R. Dohoo, G. P. Keefe, J.-P. Roy, and D. T. Scholl. 2011. The National Cohort of Dairy Farms - A data collection platform for mastitis research in Canada . J. Dairy Sci. 94:16161626 .

Robert, A., N. Bareille, P. Roussel, B. Poutrel, V. Heuchel, and H. Seegers. 2006. Interdependence of udder quarters for new intramammary infection during the dry period in cows submitted to selective antibiotic therapy. J. Dairy Res. 73:345-352.

Schepers, A. J., T. J. G. M. Lam. Y. H. Schukken, J. B. M. Wilmink, and W. J. A. Hanekamp. 1997. Estimation of variance components for somatic cell counts to determine thresholds for uninfected quarters. J. Dairy Sci. 80:1833-1840.

Schultze, W. D., and A. J. Bramley. 1982. Effect of Escherichia coli endotoxin-mediated inflammation of one mammary quarter on the bovine udder on diapedesis into other quarters. J. Dairy Res. 49:381-385.

Smith, A., and H. G. J. Coetzee. 1978. Distribution of udder infections between cows and between quarters within cows. S. Afr. J. Dairy Technol. 10:131-132.

Supré, K., F. Haesebrouck, R. N. Zadoks, M. Vaneechoutte, S. Piepers, and S. De Vliegher. 2011. Some coagulase-negative Staphylococcus species affect udder health more than others. J. Dairy Sci. 94:2329-2340

Swenson, G. H. 1979. Posology and field efficacy study with novobiocin for intramammary infusion in nonlactating dairy cows. Can. J. Comp. Med. 43:440-447.

Vigre, H., I. R. Dohoo, H. Stryhn, and M. E. Busch. 2004. Intra-unit correlations in sero-conversion to Actinobacillus pleuropneumoniae and Mycoplasma hypneumoniae at different levels in Danish multisite pig production facilities. Prev. Vet. Med. 63:9-28.

Walker, J. B., P. J. Rajala-Schultz, W. L. Walker, J. L. Mathews, W. A. Gebreyes, and F. J. DeGraves. 2011. Variation in daily shedding patterns of Staphylococcus aureus in naturally occurring intramammary infections. J. Vet. Diagn. Invest. 23:1114-1122.

Wever, P., and U. Emanuelson. 1989. Effects of systematic and intramammary infection on differential and total somatic cell counts in quarter milk samples from dairy cows. Acta Vet. Scand. 30:465474

Zadoks, R. N., H. G. Allore, H. W. Barkema, O. C. Sampimon, Y. T. Grohn, and Y. H. Schukken. 2001a. Analysis of an outbreak of Streptococcus uberis mastitis. J. Dairy Sci. 84:590-599.

Zadoks, R. N., H. G. Allore, H. W. Barkema, O. C. Sampimon, G. J. Wellenberg, Y. T. Grohn, and Y. H. Schukken. 2001b. Cow- and quarter-level risk factors for Streptococcus uberis and Staphylococcus aureus mastitis. J. Dairy Sci. 84:2649-2663.

Zadoks, R. N., B. E. Gillespie, H. W. Barkema, O. C. Sampimon, S. P. Oliver, and Y. H. Schukken. 2003. Clinical, epidemiological and molecular characteristics of Streptococcus uberis infections in dairy herds. Epidemiol. Infect. 130:335-349. 